\title{
A systematic review of endoscopic versus open treatment of craniosynostosis. Part 2: the nonsagittal single sutures
}

\author{
${ }^{*}$ Han Yan, MD,, Taylor J. Abel, MD, ${ }^{2}$ Naif M. Alotaibi, MD, MSc, ${ }^{1}$ Melanie Anderson, MLIS, ${ }^{3}$ \\ Toba N. Niazi, MD, ${ }^{4}$ Alexander G. Weil, MD, ${ }^{5}$ Aria Fallah, MD, MSc, ${ }^{6}$ John H. Phillips, MD, MA, \\ Christopher R. Forrest, MD, MSc, ${ }^{7}$ Abhaya V. Kulkarni, MD, PhD, ${ }^{1,2}$ \\ James M. Drake, MBBCh, MSc, ${ }^{1,2}$ and George M. Ibrahim, MD, PhD',2 \\ 1Division of Neurosurgery, Department of Surgery, University of Toronto; ${ }^{2}$ Division of Neurosurgery, The Hospital for Sick \\ Children, Toronto; ${ }^{2}$ Library and Information Services, University Health Network, University of Toronto, Ontario, Canada; \\ ${ }^{4}$ Division of Neurosurgery, Nicklaus Children's Hospital, University of Miami Miller School of Medicine, Miami, Florida; ${ }^{5}$ Division \\ of Neurosurgery, CCHU-Ste-Justine Children's, Montreal, Quebec, Canada; ${ }^{\circ D e p a r t m e n t ~ o f ~ N e u r o s u r g e r y, ~ M a t t e l ~ C h i l d r e n ' s ~}$ \\ Hospital, David Geffen School of Medicine at University of California Los Angeles, California; and 'Division of Plastic and \\ Reconstructive Surgery, Department of Surgery, University of Toronto, Ontario, Canada
}

OBJECTIVE Despite increasing adoption of endoscopic techniques for repair of nonsagittal single-suture craniosynostosis, the efficacy and safety of the procedure relative to established open approaches are unknown. In this systematic review the authors aimed to directly compare open surgical and endoscope-assisted techniques for the treatment of metopic, unilateral coronal, and lambdoid craniosynostosis, with an emphasis on quantitative reported outcomes.

METHODS A literature search was performed in compliance with the Preferred Reporting Items for Systematic Reviews and Meta-Analyses (PRISMA) guidelines. Relevant articles were identified from 3 electronic databases (MEDLINE, EMBASE, and CENTRAL [Cochrane Central Register of Controlled Trials]) from their inception to August 2017. The quality of methodology and bias risk were assessed using the Effective Public Health Practice Project (EPHPP) Quality Assessment Tool for Quantitative Studies.

RESULTS Of 316 screened records, 7 studies were included in a qualitative synthesis of the evidence, of which none were eligible for meta-analysis. These reported on 111 unique patients with metopic, 65 with unilateral coronal, and 12 with lambdoid craniosynostosis. For all suture types, 100 (53\%) children underwent endoscope-assisted craniosynostosis surgery and $32(47 \%)$ patients underwent open repair. These studies all suggest that blood loss, transfusion rate, operating time, and length of hospital stay were superior for endoscopically treated children. Although potentially comparable or better cosmetic outcomes are reported, the paucity of evidence and considerable variability in outcomes preclude meaningful conclusions.

CONCLUSIONS Limited data comparing open and endoscopic treatments for metopic, unilateral coronal, and lambdoid synostosis suggest a benefit for endoscopic techniques with respect to blood loss, transfusion, length of stay, and operating time. This report highlights shortcomings in evidence and gaps in knowledge regarding endoscopic repair of nonsagittal single-suture craniosynostosis, emphasizing the need for further matched-control studies.

https://thejns.org/doi/abs/10.3171/2018.4.PEDS17730

KEYWORDS craniosynostosis; endoscopic; nonsagittal suture; craniofacial

A LTHOUGH emerging data from the endoscopic treatment of sagittal synostosis suggest more favorable perioperative outcomes, there is substantially less data to inform decisions for the surgical treatment of nonsagittal single-suture craniosynostosis. Metopic cranio- synostosis, or trigonocephaly, is often characterized by a triangular anterior cranial vault, bitemporal narrowing with biparietal expansion, or midline forehead ridging. The incidence of metopic synostosis has been estimated to be as high as 1 in 5000 births, ${ }^{23}$ and accounts for $10 \%$ of

ABBREVIATIONS EBL = estimated blood loss; EPHPP = Effective Public Health Practice Project; PRISMA = Preferred Reporting Items for Systematic Reviews and Meta-

Analyses.

SUBMITTED January 29, 2018. ACCEPTED April 3, 2018.

INCLUDE WHEN CITING Published online July 6, 2018; DOI: 10.3171/2018.4.PEDS17730.

${ }^{*}$ H.Y. and T.J.A. contributed equally to this work. 


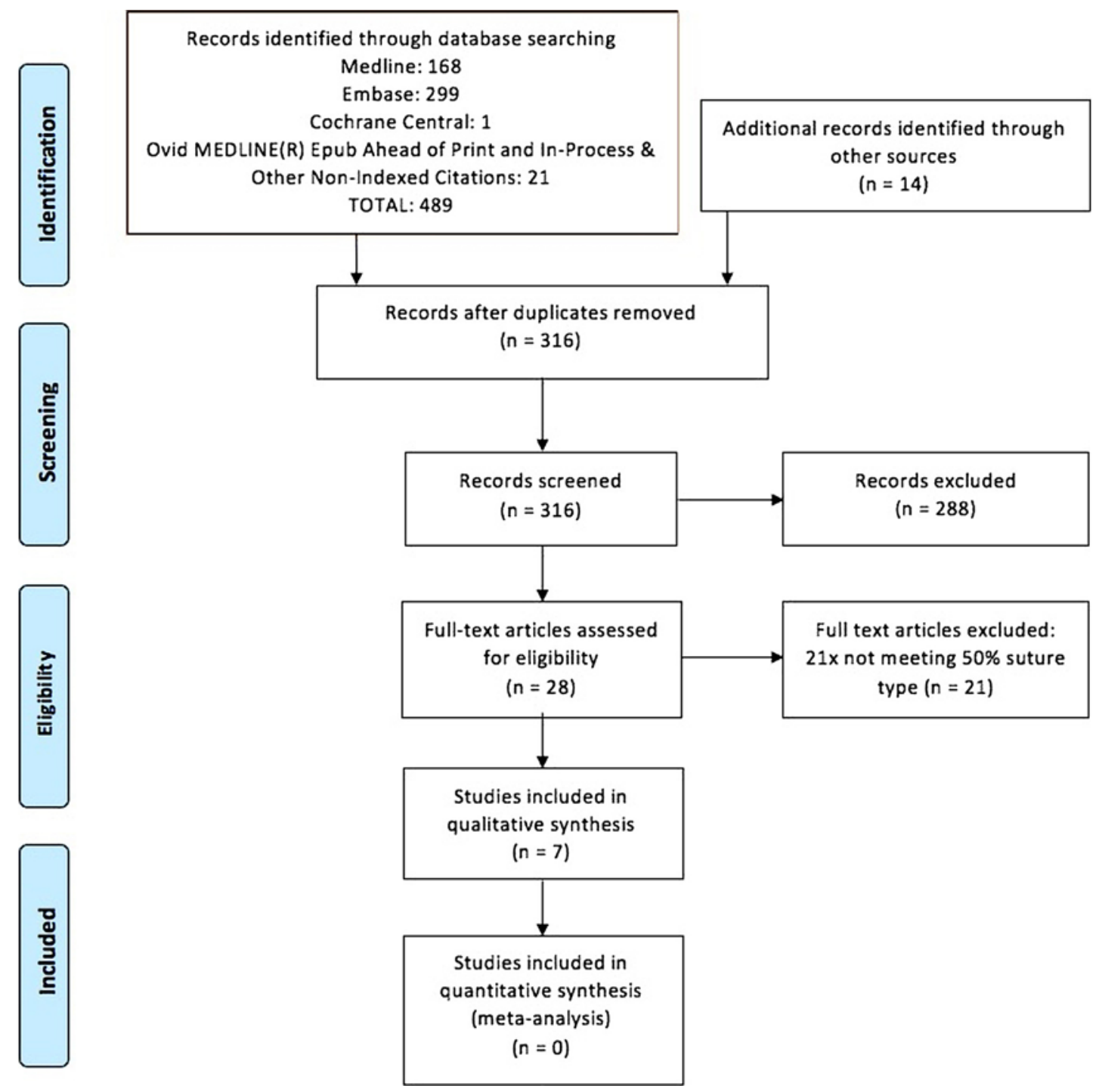

FIG. 1. PRISMA flowchart for systematic review. Figure is available in color online only.

all craniosynostoses. ${ }^{15}$ Unilateral coronal craniosynostosis is the most common cause of synostotic frontal plagiocephaly. It is characterized by frontal and superior orbital retrusion on the fused side, sometimes resulting in strabismus. ${ }^{26}$ The incidence is estimated to be approximately 66 in 1 million live births. ${ }^{31}$ Lambdoid craniosynostosis is characterized by flattening of the occipital bone, leading to potential cranial vault deformity. Lambdoid suture synostosis is rare, representing $1 \%$ to $4 \%$ of all cases of craniosynostosis, and occurs once in every 40,000 live births. ${ }^{39}$

There is still controversy around the cosmetic and neurodevelopmental indications for surgical treatment of craniosynostosis. ${ }^{34,45,46}$ In milder forms, the diagnosis may be difficult and the natural course can be self-limited and self-correcting. ${ }^{8}$ However, because a fused suture may physically limit normal brain development, surgery is often offered to correct the deformity before the age of 1 year. ${ }^{1,6,37}$ Metopic synostosis has shown the greatest correlation with neurodevelopmental delay when compared to other single-suture synostoses ${ }^{43}$ although it is yet unproven if corrective cranioplasty rectifies developmental problems.

The variety of synostosis presentation necessitates a variety of surgical techniques. The operative procedure is often tailored to the severity of the deformity. Open surgery techniques for metopic synostosis include synostectomy, ${ }^{3}$ the "floating head" cranial vault expansion, ${ }^{28}$ and fronto-orbital reshaping and expansion with bone grafts..$^{2,18}$ Unilateral coronal synostosis has been treated with open surgical techniques that include forward advancement of the supraorbital bar and correction of the orbital asymmetry. ${ }^{2,32}$ Lambdoid synostosis requires open surgery to release the fused suture and correct the cranial vault. Endoscopic approaches to these 3 suture types include suturectomy, fronto-orbital advancement, or a combination, with helmet therapy to follow surgical treatment. ${ }^{48}$

Since its introduction in 2002, endoscopic treatment for craniosynostosis has been shown to be effective, safe, and inexpensive..$^{15,19}$ This systematic literature review aims to 
directly compare open surgical techniques and endoscopeassisted techniques for the treatment of metopic, unilateral coronal, and lambdoid synostosis. A disproportionate number of studies have focused on sagittal synostosis. Given the encouraging outcomes reported, there is greater enthusiasm to further expand indications for endoscopic repair. This review presents the most comprehensive evidence for nonsagittal single-suture craniosynostosis. Given that the data for any one specific nonsagittal suture are limited and variable, the current report evaluates several suture types in the analysis of the newer endoscopic treatments compared to traditional open surgery. We highlight deficiencies in knowledge regarding safety and efficacy of the procedure relative to more established open approaches and discuss future studies to better assess outcomes in this heterogeneous patient population.

\section{Methods}

\section{Search Strategy}

This systematic review was conducted according to the Preferred Reporting Items for Systematic Reviews and Meta-Analyses (PRISMA) guidelines and recommendations. ${ }^{25,36}$ A literature search was performed on MEDLINE, EMBASE, and CENTRAL (Cochrane Central Register of Controlled Trials) on August 17, 2017, by a librarian (M.A.). The database searches used keywords (individually and/or in combination) such as "craniosynostosis," "endoscopic," and "neuroendoscope" with the appropriate subject headings. The reference lists of retrieved articles were reviewed to identify additional relevant articles. Prior to submission, another search was conducted to include newly published studies.

\section{Study Selection}

Retrieved studies were systematically assessed using inclusion and exclusion criteria by 2 reviewers (H.Y. and T.J.A.). Inclusion criteria were 1) diagnosis of metopic, unilateral coronal, or lambdoid craniosynostosis by a plastics surgeon or neurosurgeon; 2) at least $50 \%$ of the patient population had isolated metopic, unilateral coronal, or lambdoid craniosynostosis; and 3) cohorts were divided into open surgery and endoscopically assisted surgery. Exclusion criteria for the meta-analysis included 1) lack of quantitative comparison between open surgery and endoscopically assisted surgery; 2) nonhuman subjects; 3) inclusion of patients with syndromic craniosynostosis; and 4) editorials, abstracts, review articles, case reports, and dissertations. When duplicate studies were found, only the most complete reports were included for quantitative assessment.

\section{Data Extraction and Critical Appraisal}

All data were extracted from article texts, tables, and figures. Each retrieved article was reviewed by 2 investigators independently (H.Y. and T.J.A.). Authors were contacted when there were missing or incomplete data. The quality of the methodology and the risk of bias across studies were assessed by 1 reviewer (H.Y.) using the Effective Public Health Practice Project (EPHPP) Quality Assessment Tool for Quantitative Studies. ${ }^{41}$ Measured vari-
TABLE 1. Exclusion of eligible studies

\begin{tabular}{|c|c|c|}
\hline Authors \& Year & Excluded & Explanations \& Comments \\
\hline Abbott et al., 2012 & Yes & Pts w/ sagittal craniosynostosis only \\
\hline Arts et al., 2018 & No & $\begin{array}{l}\text { Analyzed pts w/ metopic craniosyn- } \\
\text { ostosis separately }\end{array}$ \\
\hline Bonfield et al., 2016 & Yes & Pts w/ sagittal craniosynostosis only \\
\hline Chan et al., 2013 & Yes & $\begin{array}{l}\text { Includes pts w/ syndromic cra- } \\
\text { niosynostosis; pts w/ metopic } \\
\text { craniosynostosis represent } 21 \% \\
\text { of cohort }\end{array}$ \\
\hline $\begin{array}{l}\text { Dvoracek et al., } \\
2015\end{array}$ & Yes & $\begin{array}{l}\text { Pts w/ sagittal craniosynostosis } \\
\text { only; overlapping pt population } \\
\text { suspected }\end{array}$ \\
\hline $\begin{array}{l}\text { Esparza \& Hino- } \\
\text { josa, } 2008\end{array}$ & Yes & Pts w/ sagittal craniosynostosis only \\
\hline Farber et al., 2017 & No & NA \\
\hline Garber et al., 2017 & Yes & Pts w/ sagittal craniosynostosis only \\
\hline Ghenbot et al., 2015 & Yes & Pts w/ sagittal craniosynostosis only \\
\hline Ghosh et al., 2014 & Yes & Pts w/ sagittal craniosynostosis only \\
\hline Han et al., 2016 & Yes & $\begin{array}{l}\text { Pts w/ metopic craniosynostosis } \\
\text { represent }<17 \% \text { of cohort }\end{array}$ \\
\hline Hashim et al., 2014 & Yes & $\begin{array}{l}\text { Analysis of neuropsychological } \\
\text { outcomes only }\end{array}$ \\
\hline $\begin{array}{l}\text { Keshavarzi et al., } \\
2009\end{array}$ & No & NA \\
\hline $\begin{array}{l}\text { Keshavarzi et al., } \\
2010\end{array}$ & Yes & $\begin{array}{l}\text { Pts w/ metopic craniosynostosis } \\
\text { represent } 27 \% \text { of cohort }\end{array}$ \\
\hline Kohan et al., 2008 & Yes & Case studies of twin pts \\
\hline Le et al., 2014 & Yes & $\begin{array}{l}\text { Pts w/ sagittal craniosynostosis } \\
\text { only; overlapping pt population } \\
\text { suspected }\end{array}$ \\
\hline $\begin{array}{l}\text { MacKinnon et al., } \\
2009\end{array}$ & Yes & $\begin{array}{l}\text { Overlapping pt population \& data } \\
\text { suspected }\end{array}$ \\
\hline $\begin{array}{l}\text { MacKinnon et al., } \\
2013\end{array}$ & No & NA \\
\hline Nguyen et al., 2015 & No & NA \\
\hline $\begin{array}{l}\text { Nowaková et al., } \\
2015\end{array}$ & Yes & $\begin{array}{l}\text { Translated from Czech; nonquanti- } \\
\text { tative data }\end{array}$ \\
\hline Rogers et al., 2015 & Yes & $\begin{array}{l}\text { Measured outcome is hand prefer- } \\
\text { ence }\end{array}$ \\
\hline Shah et al., 2011 & Yes & Pts w/ sagittal craniosynostosis only \\
\hline Siu et al., 2014 & Yes & $\begin{array}{l}\text { Case studies of } 2 \text { pts w/ unilat } \\
\text { coronal craniosynostosis \& Down } \\
\text { syndrome }\end{array}$ \\
\hline Tan et al., 2013 & No & NA \\
\hline $\begin{array}{l}\text { Thompson et al., } \\
2018\end{array}$ & Yes & $\begin{array}{l}\text { Pts w/ metopic craniosynostosis } \\
\text { represent } 18 \% \text { of cohort }\end{array}$ \\
\hline Vogel et al., 2014 & Yes & $\begin{array}{l}\text { Pts w/ unilat coronal craniosynos- } \\
\text { tosis only }\end{array}$ \\
\hline $\begin{array}{l}\text { Yarbrough et al., } \\
2014\end{array}$ & Yes & $\begin{array}{l}\text { Case series of } 5 \text { pts w/ mixed suture } \\
\text { types }\end{array}$ \\
\hline Zubovic et al., 2015 & No & NA \\
\hline
\end{tabular}

$\mathrm{NA}=$ not applicable; pts = patients. 
TABLE 2. Demographic characteristics of patients in literature review studies

\begin{tabular}{|c|c|c|c|c|c|c|c|c|c|c|c|c|c|}
\hline \multirow[b]{3}{*}{ Authors \& Year } & \multirow{3}{*}{$\begin{array}{l}\text { City \& State or } \\
\text { Country }\end{array}$} & \multirow{3}{*}{$\begin{array}{l}\text { EPHPP } \\
\text { Rating }\end{array}$} & \multirow[b]{3}{*}{ Suture Type } & \multirow{3}{*}{$\begin{array}{l}\text { Study } \\
\text { Design }\end{array}$} & \multirow{3}{*}{$\begin{array}{l}\text { No. of } \\
\text { Pts }\end{array}$} & \multirow{2}{*}{\multicolumn{2}{|c|}{$\begin{array}{l}\text { No. of Pts } \\
\text { Treated }\end{array}$}} & \multirow{2}{*}{\multicolumn{2}{|c|}{ Mean Age (mos) }} & \multirow{2}{*}{\multicolumn{2}{|c|}{$\%$ Male }} & \multirow{2}{*}{\multicolumn{2}{|c|}{ FU (mos) }} \\
\hline & & & & & & & & & & & & & \\
\hline & & & & & & Endo & Open & Endo & Open & Endo & Open & Endo & Open \\
\hline Arts et al., 2018 & $\begin{array}{l}\text { Nijmegen, } \\
\text { Netherlands }\end{array}$ & Strong & Metopic & ROS & 50 & 35 & 15 & $3.6 \pm 1.1$ & $10 \pm 2.9$ & \multicolumn{2}{|c|}{ NR } & \multicolumn{2}{|r|}{12} \\
\hline Farber et al., 2017 & St. Louis, MO & Weak & Metopic & ROS & $26^{*}$ & $13^{*}$ & $13^{*}$ & \multicolumn{2}{|c|}{ NR } & \multicolumn{2}{|c|}{ NR } & \multicolumn{2}{|c|}{12} \\
\hline $\begin{array}{l}\text { Keshavarzi et al., } \\
2009\end{array}$ & San Diego, CA & Moderate & Metopic & ROS & 33 & 16 & 17 & 4.9 & 29.5 & 88 & 65 & \multicolumn{2}{|c|}{$>36$} \\
\hline Nguyen et al., 2015 & St. Louis, MO & Weak & Metopic & ROS & 28 & 13 & 15 & $3.3 \pm 0.4$ & $9.5 \pm 1.8$ & 70 & 70 & \multicolumn{2}{|c|}{12} \\
\hline $\begin{array}{l}\text { MacKinnon et al., } \\
2013\end{array}$ & Boston, MA & Weak & Unilat coronal & ROS & 43 & 21 & 22 & 4.0 & 9.3 & \multicolumn{2}{|c|}{ NR } & 23.5 & 21.5 \\
\hline Tan et al., 2013 & Boston, MA & Moderate & Unilat coronal & ROS & 22 & 11 & 11 & 2 & 12 & \multicolumn{2}{|c|}{ NR } & 34.5 & 45.9 \\
\hline Zubovic et al., 2015 & St. Louis, MO & Weak & Lambdoid & ROS & 12 & 4 & 8 & 5.5 & 12.8 & \multicolumn{2}{|c|}{ NR } & \multicolumn{2}{|c|}{ NR } \\
\hline
\end{tabular}

Endo = endoscopically assisted surgery; FU = follow-up; $N R$ = not recorded; OS = observational study; $R$ = retrospective.

The mean values are expressed \pm SD in studies in which SD was reported.

* These patients considered non-unique because of notable similarities with the Nguyen et al. cohort.

ables included selection bias, study design, confounders, blinding, data collection methods, withdrawals and dropouts, as well as a global rating, and the tool rates each as "strong," "moderate," or "weak."

\section{Results}

\section{Literature Search}

The search strategy identified a total of 503 studies (Fig. 1). After removal of 187 duplicate studies, inclusion and exclusion criteria were applied to the titles of the remaining 316 articles. This yielded 28 studies that underwent full-text analysis (Table 1), of which 21 did not meet the inclusion criteria of 1) having more than $50 \%$ of patients present with metopic, unilateral coronal, or lambdoid synostosis; and 2) reporting on quantitative results. Two of the studies reported on the same cohort, although analyses were focused on different outcome metrics. ${ }^{11,29}$ Due to a dearth of studies with uniform quantitative data, a meta-analysis could not be conducted.

\section{Cohort Description}

The cohort size of the literature review included 111 unique patients with metopic craniosynostosis, 65 patients with unilateral coronal craniosynostosis, and 12 patients with lambdoid craniosynostosis. Of the 7 studies included, only the patients in the Farber et al. ${ }^{11}$ cohort were considered non-unique patients because of notable similarities with the cohort in Nguyen et al. ${ }^{29}$ If these 26 patients, 13 in each group, are not counted separately from the patients in the Nguyen et al. cohort, then 100 (53\%) children underwent endoscope-assisted craniosynostosis surgery and 88 $(47 \%)$ patients underwent open repair (Table 2). The age of the endoscopically treated cohort was generally younger than that of the open cohort (range 2.0-5.5 months and 9.3-29.5 months, respectively).

\section{Perioperative Outcomes}

Two studies ${ }^{4,20}$ were able to calculate the mean estimated blood loss (EBL) for patients with metopic craniosynostosis treated with endoscopic (range 39-57 ml) and open surgery (range 190-218 ml); endoscopic procedures were favored (Table 3). Similarly, patients with metopic craniosynostosis benefitted from lower transfusion rates when surgery was done endoscopically (range 17\%-62\%) compared to open (range 71\%-100\%) procedures. For patients with metopic craniosynostosis, only Keshavarzi et al. ${ }^{20}$ demonstrated lower transfusion volumes $(91.9 \mathrm{ml}$ vs $184 \mathrm{ml}$ ), shorter operating time (1.7 hours vs 2.21 hours), and shorter length of stay in hospital (2.46 days vs 2.76

TABLE 3. Perioperative outcomes of patients in literature review studies

\begin{tabular}{|c|c|c|c|c|c|c|c|c|c|c|c|c|}
\hline \multirow[b]{2}{*}{ Authors \& Year } & \multirow{2}{*}{$\begin{array}{l}\text { No. of } \\
\text { Pts }\end{array}$} & \multirow[b]{2}{*}{ Suture Type } & \multicolumn{2}{|c|}{ Mean EBL (ml) } & \multicolumn{2}{|c|}{ Mean Transfusion Vol (ml) } & \multicolumn{2}{|c|}{$\%$ Transfused } & \multicolumn{2}{|c|}{ Op Time (hrs) } & \multicolumn{2}{|c|}{ LOS (days) } \\
\hline & & & Endo & Open & Endo & Open & Endo & Open & Endo & Open & Endo & Open \\
\hline \multirow[t]{4}{*}{ Arts et al., 2018} & 50 & Metopic & $39 \pm 25$ & $218 \pm 167$ & & & 17 & 100 & \multicolumn{2}{|c|}{ NR } & \multicolumn{2}{|c|}{ NR } \\
\hline & 3 & Coronal & 10 & $110 \pm 85$ & \multicolumn{2}{|c|}{ NR } & 0 & 100 & \multicolumn{2}{|c|}{ NR } & \multicolumn{2}{|c|}{ NR } \\
\hline & 26 & Plagiocephaly & $33 \pm 25$ & $194 \pm 124$ & \multicolumn{2}{|c|}{ NR } & 0 & 100 & \multicolumn{2}{|c|}{ NR } & \multicolumn{2}{|c|}{ NR } \\
\hline & 6 & Multisuture & $65 \pm 36$ & $207 \pm 90$ & \multicolumn{2}{|c|}{ NR } & 33 & 100 & \multicolumn{2}{|c|}{ NR } & \multicolumn{2}{|c|}{ NR } \\
\hline Keshavarzi et al., 2009 & 33 & Metopic & 56.8 & 190 & 91.9 & 184 & 62 & 71 & 1.68 & 2.21 & 2.46 & 2.76 \\
\hline Zubovic et al., 2015 & 12 & Lambdoid & 15 & 350 & \multicolumn{2}{|c|}{ NR } & 0 & 100 & 0.98 & 5.0 & \multicolumn{2}{|c|}{ NR } \\
\hline
\end{tabular}

LOS = length of stay. 
days) for endoscopic procedures compared to open surgery, although no statistical analysis was performed.

Arts et al. ${ }^{4}$ analyzed patients with coronal sutures, plagiocephaly, and multisutures, and Zubovic et al. ${ }^{49}$ analyzed 12 patients with lambdoid craniosynostosis. Consistently across suture types, endoscopically treated patients had lower mean EBL (range 10-65 ml) compared to patients with open surgery (range 110-350 ml). Analogously, the transfusion rate was consistently lower for endoscopically treated patients (range 0\%-33\%) compared to patients treated with open surgery (100\%). Zubovic et al. also demonstrated that the operating time for endoscopic lambdoid procedures was lower, at 0.98 hours, compared to 5.0 hours for open lambdoid surgery.

\section{Cosmetic Outcomes}

Two studies ${ }^{11,29}$ reported on cosmetic outcomes for patients with metopic craniosynostosis (Table 4). The postoperative outcomes do not show a difference with regard to mean frontal width $(80 \mathrm{~mm}$ vs $81 \mathrm{~mm})$, mean interzygomaticofrontal distance (77.0 $\mathrm{mm}$ vs $76.2 \mathrm{~mm}, \mathrm{p}=0.68$ ), mean intercanthal distance $(30.3 \mathrm{~mm}$ vs $31.0 \mathrm{~mm}, \mathrm{p}=$ $0.61)$, interfrontal angle $\left(112.5^{\circ}\right.$ vs $\left.112.6^{\circ}, \mathrm{p}=0.98\right)$, or interzygomaticofrontal distance $\left(109.0^{\circ}\right.$ vs $\left.109.8^{\circ}, \mathrm{p}=0.73\right)$. These cosmetic outcomes were measured at a minimum of 12 months after the operation.

Tan et al. ${ }^{40}$ analyzed the cosmetic outcomes for unilateral coronal synostosis (Table 4). They determined that there was no difference between endoscopic and open procedures with regard to supraorbital symmetry $(\mathrm{p}=0.054)$. The endoscopically treated patients exhibited better facial symmetry in midline deviation $(\mathrm{p}=0.018)$ and nasal tip deviation $(\mathrm{p}=0.006)$. Zubovic et al ${ }^{49}$ studied the cosmetic outcomes for unilateral lambdoid synostosis. At 1 year postoperatively, open and endoscopically treated patients were statistically equivalent in all measures (range, $\mathrm{p}=$
0.359 to $\mathrm{p}=0.967)$, and mean volume asymmetry was significantly improved in both groups.

MacKinnon et al. ${ }^{26}$ specifically studied the ophthalmic outcomes in children with unilateral coronal synostosis, showing that children treated with fronto-orbital advancement open surgery were more likely to develop amblyopia $(p=0.0015)$ and to receive surgery to correct their strabismus.

These retrospective observational studies were assessed by the EPHPP Quality Assessment Tool to include 4 weak, 2 moderate, and 1 strong study (Table 5). Blinding was either not possible or neglected in the methodology. The data collection and statistical analyses of these studies were rigorous, although the small patient population causes difficulty in finding and adjusting for confounders.

\section{Discussion}

In this literature review, we found 4 studies ${ }^{4,11,20,29}$ that support the surgical treatment of metopic synostosis by endoscope-assisted surgery compared with open surgery. Two studies ${ }^{26,40}$ examined unilateral coronal surgery outcomes, and 1 study ${ }^{49}$ evaluated lambdoid synostosis. Based on limited data, endoscopic techniques were associated with better perioperative outcomes. Given the heterogeneity in presentations and procedures, strong conclusions cannot be formulated regarding cosmetic results, although objective indicators of cosmesis were equivocal in the few studies reporting these outcomes.

Two studies ${ }^{4,20}$ demonstrated that endoscopic procedures for patients with metopic craniosynostosis have a lower EBL and lower transfusion volumes, shorter operating time, and shorter hospital stay. These results highlighted, however, the fact that the lower blood loss may only be possible with the availability of appropriate instruments, such as a bone scalpel. Similar trends were reported for unilateral coronal synostosis and lambdoid synostosis., ${ }^{4,49}$

TABLE 4. Reported cosmetic outcomes comparing endoscopic and open treatment

\begin{tabular}{|c|c|c|c|c|c|c|c|}
\hline \multirow[b]{2}{*}{ Authors \& Year } & \multicolumn{2}{|c|}{ No. of Pts } & \multirow[b]{2}{*}{ Suture Type } & \multirow[b]{2}{*}{ Outcomes } & \multicolumn{2}{|c|}{ Treatment } & \multirow{2}{*}{$\begin{array}{c}p \\
\text { Value }\end{array}$} \\
\hline & Endo & Open & & & Endo & Open & \\
\hline \multirow[t]{2}{*}{ Farber et al., 2017} & \multirow[t]{2}{*}{13} & \multirow[t]{2}{*}{13} & Metopic & Mean frontal width $(\mathrm{mm})$ & $80 \pm 0.4$ & $81 \pm 0.7$ & \\
\hline & & & & Z-score & 0.0 & 0.0 & \\
\hline \multirow[t]{4}{*}{ Nguyen et al., 2015} & \multirow[t]{4}{*}{13} & \multirow[t]{4}{*}{15} & Metopic & Mean ZF-ZF (mm) & $77.0 \pm 0.8$ & $76.2 \pm 1.8$ & 0.68 \\
\hline & & & & Mean ID (mm) & $30.3 \pm 0.7$ & $31.0 \pm 1.0$ & 0.61 \\
\hline & & & & ZFr-G-ZFI & $109.0^{\circ} \pm 1.6^{\circ}$ & $109.8^{\circ} \pm 2.0^{\circ}$ & 0.73 \\
\hline & & & & IFA & $112.5^{\circ} \pm 1.9^{\circ}$ & $112.6^{\circ} \pm 2.8^{\circ}$ & 0.98 \\
\hline \multirow[t]{3}{*}{ Tan et al., 2013} & \multirow[t]{3}{*}{11} & \multirow[t]{3}{*}{11} & Unilat coronal & Nasal tip deviation & $2.3^{\circ} \pm 1.8^{\circ}$ & $5.6^{\circ} \pm 3.0^{\circ}$ & 0.006 \\
\hline & & & & Facial midline deviation & $1.4^{\circ} \pm 1.1^{\circ}$ & $3.6^{\circ} \pm 2.4^{\circ}$ & 0.018 \\
\hline & & & & Difference btwn It \& rt brow projection (mm) & $1.7 \pm 0.9$ & $1.0 \pm 0.6$ & 0.054 \\
\hline \multirow[t]{5}{*}{ Zubovic et al., 2015} & \multirow[t]{5}{*}{4} & \multirow[t]{5}{*}{8} & Lambdoid & PFA & $6.4^{\circ}$ & $6.6^{\circ}$ & 0.691 \\
\hline & & & & PRA & $9.5^{\circ}$ & $7.9^{\circ}$ & 0.551 \\
\hline & & & & MCA & $3.2^{\circ}$ & $4.0^{\circ}$ & 0.967 \\
\hline & & & & Vertical EAM displacement (mm) & -2.3 & -2.3 & 0.359 \\
\hline & & & & Anterior-posterior EAM displacement (mm) & 7.8 & 6.8 & 0.459 \\
\hline
\end{tabular}

EAM = external acoustic meatus; $I D=$ intercanthal distance; IFA = interfrontal angle; $M C A=$ mastoid cant angle; PFA = posterior fossa deflection angle; PRA = petrous ridge angle; ZF = zygomaticofrontal; ZF-ZF = inter-ZF distance; ZFr-G-ZFI = right ZF-glabella-left ZF angle (i.e., axial bilateral zygomaticofrontal-glabella angle). 
TABLE 5. Results of quality assessment of methodology

\begin{tabular}{|c|c|c|c|c|c|c|c|}
\hline Authors \& Year & Selection Bias & Study Design & Confounders & Blinding & Data Collection Methods & Analyses & Global Rating \\
\hline Arts et al., 2018 & Strong & Moderate & Moderate & Moderate & Moderate & Moderate & Strong \\
\hline Farber et al., 2017 & Weak & Moderate & Weak & Moderate & Moderate & Moderate & Weak \\
\hline Keshavarzi et al., 2009 & Strong & Moderate & Weak & Moderate & Moderate & Moderate & Moderate \\
\hline Nguyen et al., 2015 & Strong & Moderate & Weak & Moderate & Weak & Moderate & Weak \\
\hline MacKinnon et al., 2013 & Moderate & Moderate & Weak & Moderate & Weak & Moderate & Weak \\
\hline Tan et al., 2013 & Strong & Moderate & Weak & Moderate & Strong & Moderate & Moderate \\
\hline Zubovic et al., 2015 & Moderate & Moderate & Weak & Moderate & Weak & Moderate & Weak \\
\hline
\end{tabular}

Cosmetic outcomes were only reported in 26 patients with metopic craniosynostosis on 1-year postoperative CT scans. ${ }^{11,29}$ Measurements of mean frontal width and interfrontal angle show no significant cosmetic difference between endoscopic and open treatment. Patients with unilateral coronal craniosynostosis seem to benefit more from endoscopic treatment, with better postoperative facial symmetry ${ }^{40}$ and a smaller risk for developing amblyopia or strabismus. ${ }^{26}$ The analysis of aesthetics is only as rigorous as the metrics available for measurement, which significantly limits the conclusions that could be derived from the literature. Ultimately, how the cosmetic outcomes of endoscopic craniosynostosis repair compare to those of open techniques remains an open question.

In larger studies in which several suture types were studied, ${ }^{7,16}$ the perioperative outcomes also seem to favor endoscopic procedures. Han et al. ${ }^{16}$ performed a detailed comparison between endoscopic and open procedures, with only $18.6 \%$ of their patients having metopic synostosis. They report similar results for endoscopic surgery: lower EBL ( $p<0.001)$, lower transfusion rates $(p<0.001)$, shorter procedure time $(\mathrm{p}<0.001)$, and shorter course in hospital $(\mathrm{p}<0.001)$. These 4 significant differences are also supported by Chan et al., ${ }^{7}$ whose cohort included patients with syndromic craniosynostosis, with $19 \%$ of their patients having metopic involvement. No studies were found specific to metopic, unilateral coronal, or lambdoid surgical correction that analyzed costs or rates of complication between endoscopic and open procedures.

Given the complex indications for surgery surrounding fused metopic sutures, and the variability of the degree of the deformity, minimally invasive endoscopic approaches may be a preferred option in the future. Although the early literature demonstrates safety and efficacy, a survey of 102 craniofacial surgeons demonstrates that only $19 \%$ of surgeons performed endoscopic procedures on mild cases of metopic synostosis. ${ }^{48}$ There has not yet been any analysis of the satisfaction of parents and patients with an extended length of helmet therapy. Furthermore, it is unclear at what ages children are most likely to benefit from one treatment versus another.

Strengths of this study include an extensive search of the current literature, strict adherence to PRISMA guidelines, and quality of evidence analysis by EPHPP protocol. Currently, there is a dearth of literature that directly compares endoscopic and open techniques for the treatment of metopic, unilateral coronal, or lambdoid synostosis. The greatest limitation of this study is the inclusion of several suture types, although the analysis suggests similar findings. Most of the studies included in this analysis were of weak or moderate quality, consisting of retrospective observational studies; one study was found to be strong. Longitudinal studies with extensive follow-up are required to be able to analyze the long-term cost, neurological sequelae, and cosmetic results.

\section{Conclusions}

Endoscope-assisted correction of metopic, unilateral coronal, or lambdoid synostosis shows early benefits over open surgical repair. In 7 studies that directly compared endoscopic and open procedures, there were comparable postoperative cosmetic results and better perioperative outcomes such as less blood loss, shorter operations, and shorter hospital stays. Current evidence in the literature comparing endoscopic and open craniosynostosis repair is mostly of weak to moderate quality. Future large prospective registries or randomized controlled trials are required to study long-term outcomes and to explore multiple sources of heterogeneity.

\section{References}

1. Abbott MM, Rogers GF, Proctor MR, Busa K, Meara JG: Cost of treating sagittal synostosis in the first year of life. $\mathbf{J}$ Craniofac Surg 23:88-93, 2012

2. Anderson FM: Treatment of coronal and metopic synostosis: 107 cases. Neurosurgery 8:143-149, 1981

3. Anderson FM, Gwinn JL, Todt JC: Trigonocephaly. Identity and surgical treatment. J Neurosurg 19:723-730, 1962

4. Arts S, Delye H, van Lindert EJ: Intraoperative and postoperative complications in the surgical treatment of craniosynostosis: minimally invasive versus open surgical procedures. J Neurosurg Pediatr 21:112-118, 2018

5. Bonfield CM, Sharma J, Cochrane DD, Singhal A, Steinbok P: Minimizing blood transfusions in the surgical correction of craniosynostosis: a 10-year single-center experience. Childs Nerv Syst 32:143-151, 2016

6. Bottero L, Lajeunie E, Arnaud E, Marchac D, Renier D: Functional outcome after surgery for trigonocephaly. Plast Reconstr Surg 102:952-960, 1998

7. Chan JW, Stewart CL, Stalder MW, St Hilaire H, McBride L, Moses MH: Endoscope-assisted versus open repair of craniosynostosis: a comparison of perioperative cost and risk. J Craniofac Surg 24:170-174, 2013

8. Dominguez R, Oh KS, Bender T, Girdany BR: Uncomplicated trigonocephaly. A radiographic affirmation of conservative therapy. Radiology 140:681-688, 1981

9. Dvoracek LA, Skolnick GB, Nguyen DC, Naidoo SD, Smyth 
MD, Woo AS, et al: Comparison of traditional versus normative cephalic index in patients with sagittal synostosis: measure of scaphocephaly and postoperative outcome. Plast Reconstr Surg 136:541-548, 2015

10. Esparza J, Hinojosa J: Complications in the surgical treatment of craniosynostosis and craniofacial syndromes: apropos of 306 transcranial procedures. Childs Nerv Syst 24:1421-1430, 2008

11. Farber SJ, Nguyen DC, Skolnick GB, Naidoo SD, Smyth MD, Patel KB: Anthropometric outcome measures in patients with metopic craniosynostosis. J Craniofac Surg 28:713-716, 2017

12. Garber ST, Karsy M, Kestle JRW, Siddiqi F, Spanos SP, RivaCambrin J: Comparing outcomes and cost of 3 surgical treatments for sagittal synostosis: a retrospective study including procedure-related cost analysis. Neurosurgery 81:680-687, 2017

13. Ghenbot RG, Patel KB, Skolnick GB, Naidoo SD, Smyth MD, Woo AS: Effects of open and endoscopic surgery on skull growth and calvarial vault volumes in sagittal synostosis. J Craniofac Surg 26:161-164, 2015

14. Ghosh TD, Skolnick G, Nguyen DC, Sun H, Patel K, Smyth $\mathrm{MD}$, et al: Calvarial thickness and diploic space development in children with sagittal synostosis as assessed by computed tomography. J Craniofac Surg 25:1050-1055, 2014

15. Gociman B, Agko M, Blagg R, Garlick J, Kestle JR, Siddiqi F: Endoscopic-assisted correction of metopic synostosis. J Craniofac Surg 24:763-768, 2013

16. Han RH, Nguyen DC, Bruck BS, Skolnick GB, Yarbrough CK, Naidoo SD, et al: Characterization of complications associated with open and endoscopic craniosynostosis surgery at a single institution. J Neurosurg Pediatr 17:361-370, 2016

17. Hashim PW, Patel A, Yang JF, Travieso R, Terner J, Losee JE, et al: The effects of whole-vault cranioplasty versus strip craniectomy on long-term neuropsychological outcomes in sagittal craniosynostosis. Plast Reconstr Surg 134:491-501, 2014

18. Havlik RJ, Azurin DJ, Bartlett SP, Whitaker LA: Analysis and treatment of severe trigonocephaly. Plast Reconstr Surg 103:381-390, 1999

19. Jimenez DF, Barone CM, Cartwright CC, Baker L: Early management of craniosynostosis using endoscopic-assisted strip craniectomies and cranial orthotic molding therapy. Pediatrics 110:97-104, 2002

20. Keshavarzi S, Hayden MG, Ben-Haim S, Meltzer HS, Cohen SR, Levy ML: Variations of endoscopic and open repair of metopic craniosynostosis. J Craniofac Surg 20:1439-1444, 2009

21. Keshavarzi S, Meltzer H, Cohen SR, Breithaupt A, Ben-Haim $\mathrm{S}$, Newman CB, et al: The risk of growing skull fractures in craniofacial patients. Pediatr Neurosurg 46:193-198, 2010

22. Kohan E, Wexler A, Cahan L, Kawamoto HK, Katchikian H, Bradley JP: Sagittal synostotic twins: reverse pi procedure for scaphocephaly correction gives superior result compared to endoscopic repair followed by helmet therapy. J Craniofac Surg 19:1453-1458, 2008

23. Kweldam CF, van der Vlugt JJ, van der Meulen JJ: The incidence of craniosynostosis in the Netherlands, 1997-2007. J Plast Reconstr Aesthet Surg 64:583-588, 2011

24. Le MB, Patel K, Skolnick G, Naidoo S, Smyth M, Kane A, et al: Assessing long-term outcomes of open and endoscopic sagittal synostosis reconstruction using three-dimensional photography. J Craniofac Surg 25:573-576, 2014

25. Liberati A, Altman DG, Tetzlaff J, Mulrow C, Gøtzsche PC, Ioannidis JP, et al: The PRISMA statement for reporting systematic reviews and meta-analyses of studies that evaluate health care interventions: explanation and elaboration. PLoS Med 6:e1000100, 2009
26. MacKinnon S, Proctor MR, Rogers GF, Meara JG, Whitecross S, Dagi LR: Improving ophthalmic outcomes in children with unilateral coronal synostosis by treatment with endoscopic strip craniectomy and helmet therapy rather than fronto-orbital advancement. J AAPOS 17:259-265, 2013

27. MacKinnon S, Rogers GF, Gregas M, Proctor MR, Mulliken JB, Dagi LR: Treatment of unilateral coronal synostosis by endoscopic strip craniectomy or fronto-orbital advancement: Ophthalmologic findings. J AAPOS 13:155-160, 2009

28. Marchac D, Renier D, Jones BM: Experience with the "floating forehead". Br J Plast Surg 41:1-15, 1988

29. Nguyen DC, Patel KB, Skolnick GB, Naidoo SD, Huang AH, Smyth MD, et al: Are endoscopic and open treatments of metopic synostosis equivalent in treating trigonocephaly and hypotelorism? J Craniofac Surg 26:129-134, 2015

30. Nowaková M, Kordoš P, Hladík M, Medřická H, Rosický J, Kaleta E et al: Endoskopické operační řešení kraniosynostóz z pohledu dětského intenzivisty. Přrehledové články 16:308311,2015

31. Oh AK, Wong J, Ohta E, Rogers GF, Deutsch CK, Mulliken JB: Facial asymmetry in unilateral coronal synostosis: longterm results after fronto-orbital advancement. Plast Reconstr Surg 121:545-562, 2008

32. Panchal J, Uttchin V: Management of craniosynostosis. Plast Reconstr Surg 111:2032-2049, 2003

33. Rogers GF, Wood BC, Amdur RL, Jeelani Y, Reddy S, Proctor MR, et al: Treatment type is associated with population hand preferences in patients with unilateral coronal synostosis: implications for functional cerebral lateralization. Plast Reconstr Surg 136:782e-788e, 2015

34. Selber J, Reid RR, Gershman B, Sonnad SS, Sutton LN, Whitaker LA, et al: Evolution of operative techniques for the treatment of single-suture metopic synostosis. Ann Plast Surg 59:6-13, 2007

35. Shah MN, Kane AA, Petersen JD, Woo AS, Naidoo SD, Smyth MD: Endoscopically assisted versus open repair of sagittal craniosynostosis: the St. Louis Children's Hospital experience. J Neurosurg Pediatr 8:165-170, 2011

36. Shamseer L, Moher D, Clarke M, Ghersi D, Liberati A, Petticrew M, et al: Preferred reporting items for systematic review and meta-analysis protocols (PRISMA-P) 2015: elaboration and explanation. BMJ 350:g7647, 2015

37. Sidoti EJ Jr, Marsh JL, Marty-Grames L, Noetzel MJ: Longterm studies of metopic synostosis: frequency of cognitive impairment and behavioral disturbances. Plast Reconstr Surg 97:276-281, 1996

38. Siu A, Rogers GF, Myseros JS, Khalsa SS, Keating RF, Magge SN: Unilateral coronal craniosynostosis and Down syndrome. J Neurosurg Pediatr 13:568-571, 2014

39. Smartt JM Jr, Reid RR, Singh DJ, Bartlett SP: True lambdoid craniosynostosis: long-term results of surgical and conservative therapy. Plast Reconstr Surg 120:993-1003, 2007

40. Tan SP, Proctor MR, Mulliken JB, Rogers GF: Early frontofacial symmetry after correction of unilateral coronal synostosis: frontoorbital advancement vs endoscopic strip craniectomy and helmet therapy. J Craniofac Surg 24:1190-1194, 2013

41. Thomas BH, Ciliska D, Dobbins M, Micucci S: A process for systematically reviewing the literature: providing the research evidence for public health nursing interventions. Worldviews Evid Based Nurs 1:176-184, 2004

42. Thompson DR, Zurakowski D, Haberkern CM, Stricker PA, Meier PM, Bannister C, et al: Endoscopic versus open repair for craniosynostosis in infants using propensity score matching to compare outcomes: a multicenter study from the Pediatric Craniofacial Collaborative Group. Anesth Analg 126:968-975, 2018

43. van der Meulen J: Metopic synostosis. Childs Nerv Syst 28:1359-1367, 2012 
44. Vogel TW, Woo AS, Kane AA, Patel KB, Naidoo SD, Smyth MD: A comparison of costs associated with endoscope-assisted craniectomy versus open cranial vault repair for infants with sagittal synostosis. J Neurosurg Pediatr 13:324-331, 2014

45. Warschausky S, Angobaldo J, Kewman D, Buchman S, Muraszko KM, Azengart A: Early development of infants with untreated metopic craniosynostosis. Plast Reconstr Surg 115:1518-1523, 2005

46. Wes AM, Paliga JT, Goldstein JA, Whitaker LA, Bartlett SP, Taylor JA: An evaluation of complications, revisions, and long-term aesthetic outcomes in nonsyndromic metopic craniosynostosis. Plast Reconstr Surg 133:1453-1464, 2014

47. Yarbrough CK, Smyth MD, Holekamp TF, Ranalli NJ, Huang $\mathrm{AH}$, Patel KB, et al: Delayed synostoses of uninvolved sutures after surgical treatment of nonsyndromic craniosynostosis. J Craniofac Surg 25:119-123, 2014

48. Yee ST, Fearon JA, Gosain AK, Timbang MR, Papay FA, Doumit G: Classification and management of metopic craniosynostosis. J Craniofac Surg 26:1812-1817, 2015

49. Zubovic E, Woo AS, Skolnick GB, Naidoo SD, Smyth MD, Patel KB: Cranial base and posterior cranial vault asymmetry after open and endoscopic repair of isolated lambdoid craniosynostosis. J Craniofac Surg 26:1568-1573, 2015

\section{Disclosures}

The authors report no conflict of interest concerning the materials or methods used in this study or the findings specified in this paper.

\section{Author Contributions}

Conception and design: Yan, Ibrahim. Acquisition of data: Abel, Yan, Anderson. Analysis and interpretation of data: Abel, Yan. Drafting the article: Abel, Yan. Critically revising the article: all authors. Reviewed submitted version of manuscript: all authors. Statistical analysis: Alotaibi. Administrative/technical/material support: Ibrahim. Study supervision: Yan, Ibrahim.

\section{Supplemental Information Companion Papers}

Yan H, Abel TJ, Alotaibi NM, Anderson M, Niazi TN, Weil AG, et al: A systematic review and meta-analysis of endoscopic versus open treatment of craniosynostosis. Part 1: the sagittal suture. DOI: 10.3171/2018.4.PEDS17729.

\section{Correspondence}

Taylor J. Abel: The Hospital for Sick Children, Toronto, ON, Canada.taylor.abel@sickkids.ca. 